\title{
Tema 8. Acoso escolar, bullying o matoneo
}

\section{Presentación}

Un tema recurrente en la actualidad para los padres de familia, entornos escolares, sociales y virtuales es el bullying. Se da cuando alguien tiene una conducta que busca dañar a otro a causa de una situación en su entorno personal y familiar, donde posiblemente este comportamiento es normal. Vamos a explorar algunas manifestaciones de esta conducta de acoso y cómo pueden intervenir los padres y docentes para transformarla.

\section{Propósito (objetivo)}

Indagar sobre las causas, manifestaciones y formas de atender a quien realiza y a quien es víctima de la conducta de acoso, bullying o matoneo, en el entorno familiar y escolar, con el fin de eliminar este tipo de agresión y de violencia del entorno de los niños y niñas. 


\section{Conceptualización general}

La intimidación o el acoso escolar, conocido también como matoneo o con el término inglés bullying es un comportamiento agresivo que implica un desequilibrio de poder o de fuerza en la medida en que los niños que intimidan utilizan su superioridad e influencia contra los demás, en especial, contra alguien que es débil física o socialmente, y quien por lo general no tiene cómo defenderse.

Si bien los niños pueden intimidar a otros usando medios más físicos, en las niñas el acoso se manifiesta, por lo general, mediante la exclusión social. Para ser considerado acoso escolar el comportamiento debe ser agresivo y repetitivo. Detrás de esta conducta suele atenderse al niño víctima; sin embargo, el problema está igualmente en el niño o joven que realiza la conducta, ¿dónde y cómo aprendió que para sentirse bien consigo mismo debe excluir, estigmatizar, disminuir, someter o agredir a otros? ¿Por qué afirma su autoconfianza en el ejercicio de un poder que hace daño? Estas preguntas invitan a reflexionar a los padres y adultos, en especial a pensar si detrás de ese ejercicio de "superioridad" y agresividad se esconde una serie de complejos de inferioridad.

\section{Clases de intimidación o de acoso escolar}

- La intimidación verbal o por comentarios: consiste en decir o escribir rumores o cosas negativas sobre otra persona, afectando su valía, su imagen y respetabilidad.

- La intimidación social: hablarle mal a alguien, maltratarlo, menospreciar lo que hace, sus cosas y las relaciones que mantiene con otras personas.

- La intimidación física: implica lastimar el cuerpo de una persona o dañar sus cosas personales.

- La intimidación virtual: se realiza por medios y redes sociales donde se busca desprestigiar, subvalorar, ridiculizar y estigmatizar a otra persona. 


\section{Algunas situaciones de matoneo o acoso escolar}

- Victimizar a otro niño o niña que está solo, en una posición débil, y hacer uso de prejuicios de tamaño, forma, género, raza, religión, vestimenta, entre otras, para subvalorarlo.

- Excluir a un niño de las actividades grupales, crear chismes o golpearlo.

- Poner sobrenombres, apodos, esconderle sus cosas, dañar sus pertenencias.

- Convocar a otros para realizar estas actividades; así se crean grupos que refuerzan o ignoran este tipo de abuso en lugar de ser compasivos y ayudar a la víctima.

\section{Cómo los padres, niños y adolescentes pueden evitar el matoneo}

Una educación para el respeto por el otro nace de una educación del respeto por uno mismo; es decir que nace en casa. Escuchar con cuidado y respeto, controlar los impulsos egoístas, aprender a respirar para controlar dichos impulsos, aprender consignas que fortalecen el valor personal y el respeto por los otros, buscar aportar soluciones cuando hay diferencias, hacer parte de grupos o mesas que solucionan diferencias, dar respuesta por las conductas que se llevan a cabo (ser responsable) y asumir las consecuencias de dichas conductas (aprender a perder, a recibir sanción) hacen parte del núcleo esencial del respeto por uno y por los otros.

Enseñar a los niños cómo ganarse el respeto por ser respetables y agradables y no porque generan miedo es una enseñanza que debe darse en casa, dado que, como indicamos antes, los niños aprenden las primeras conductas sociales por imitación, así, se le puede enseñar a ser amable y que será recordado por ello o que si es agresivo también será recordado por lo mismo.

Instruir y educar para incluir a otros, ser amables, no denigrar ni ser crueles, pero en especial para que aprendan a escuchar su diálogo interior, "la voz de la conciencia”, a desarrollar técnicas para 
tranquilizarse, a evitar el contacto físico si hay enojo, a crear escudos imaginarios de autoprotección que reafirmen el cuidado que deben tener son soportes válidos para evitar una mala solución a las controversias y conflictos.

Igualmente, es fundamental enseñar la diferencia entre responsabilidad y culpa, y que culpabilizar no ayuda a resolver los conflictos. Poner la culpa en los otros, afirmar que uno no hizo nada malo, incluso cuando se es víctima, no resuelve las situaciones. La pasividad de la víctima puede reforzar la conducta del que hace el acoso o matoneo, por ello enseñarle a hablar de manera asertiva (de forma firme, respetuosa y oportuna) puede evitarle muchas dificultades al niño. Así, asumir responsabilidad es aprender a reconocer que puse de mi parte para ocasionar un conflicto y qué hice para resolverlo y superarlo.

\section{¿Qué pueden hacer los padres frente al acoso que reciben sus hijos?}

- Observe a los niños y niñas, muéstreles que hay disposición para escucharlos sin juzgarlos, pues muchas veces temen contar que están siendo acosados, pueden sentir vergüenza o pena por no saber cómo resolverlo. Esto incrementa su malestar y sufrimiento.

- Dese cuenta si no quiere ir a estudiar, no le gusta el colegio, disminuye su apetito, tiene pesadillas, llega deprimido, no quiere hablar o si sus cosas o ropa están o han sido dañadas.

- Muéstrele que lo va a apoyar, escuchar y acompañarlo usando los mecanismos institucionales de la escuela.

- Aclárele que no debe tomar venganza ni la misma actitud con quien lo acosa o con otros niños y niñas.

- Enséñele a afrontar el acoso: hablando con asertividad, ignorando o no dándole importancia al acosador y buscando apoyo en sus amigos y profesores.

- Sea amigo de sus hijos en las redes sociales y active los filtros de las páginas web y aplicaciones para evitar que entren a páginas inadecuadas o tengan contacto con personas maliciosas. 
- Reporte los casos de intimidación a la escuela y guarde las evidencias, enséñele a su hijo a denunciar estas conductas ante los docentes y directivos.

- Si es necesario consulte a un psicopedagogo, a un psicólogo social o a un abogado que le enseñe a comprender y a afrontar la situación tanto a usted como padre, como a su hijo.

\section{¿Qué pueden hacer los padres de niños acosadores?}

- Haga con su pareja o con quienes apoyan la crianza del niño un ejercicio de evaluación autorreflexivo y observen si en el mismo núcleo familiar se llevan a cabo actitudes o comportamientos de acoso, o si se tolera este tipo de conducta en la familia.

- Fortalezca los procesos de autoestima y autovaloración de su hijo, enséñele que no tiene que dominar, desprestigiar o dañar a nadie para demostrar que es un ser valioso e importante.

- Respalde lo anterior con acciones de amor (respeto, responsabilidad y cuidado).

- Si nota que su hijo tiene actitudes o acosa de alguna forma a otros niños y niñas hable con él, explíquele el daño que puede generar y acuerde límites y compromisos.

\section{Acercamiento personal (reflexión)}

- Realice un recuento sobre situaciones en las que en el pasado usted fue o ha sido víctima de matoneo, incluso por miembros de su familia. ¿Qué hizo o ha hecho frente a ello?

- Valore si sus hijos han sido víctimas de esta conducta o si son responsables de perjudicar a otros niños con esta conducta.

- ¿Cree que sus hijos le tienen suficiente confianza para contarle lo que les sucede en la escuela o el colegio? 


\section{Actividades sugeridas}

Búsquedas en Internet y bibliotecas

Búsquedas de casos en prensa

Preguntas para debates grupales
- Busque casos de cyberbullying, describa dos casos, uno que se haya manejado de una manera adecuada y otro de forma inadecuada.

- Explore si existen redes de apoyo social específicas para acompañar a las víctimas del matoneo y del acoso escolar. Exponga al menos tres de ellas.

- Investigue sobre otras estrategias de prevención del bullying diferentes a las que aquí se presentan.

- Consulte en la prensa el reporte de casos graves de bullying, matoneo y acoso escolar. Proponga una forma de intervenir en dichos casos.

- ¿Cuáles han sido las propuestas desde las leyes y desde el Ministerio de Educación para tratar el bullying en la escuela? Exponga las principales ideas. ¿Qué propone la ley de convivencia escolar en Colombia?

- ¿La agresividad y la pasividad de los miembros de la familia contribuye o no a que sus hijos sean activos o pasivos frente al matoneo y el acoso escolar? ¿Por qué?

- ¿La cultura de la burla o mofa que se da en la televisión (programas de chismes), en la radio y en los medios masivos de información incide en la promoción del matoneo en todos los niveles de la sociedad? ¿Por qué? 


\section{Bibliografía básica}

Albores-Gallo, L., Sauceda-García, J., Ruiz-Velasco, S. y Roque-Santiago, E. (2011). El acoso escolar (bullying) y su asociación con trastornos psiquiátricos en una muestra de escolares en México. Salud Pública de México, 53(3), 220-227.

Armas, M. y Armas, B. (2005). Violencia escolar. Revista española de investigación educativa, 13(50), 7.

Arón, A. (2008). Un programa de educación para la no violencia. En C. Berger y C. Lisboa (eds.), Violencia escolar: Estudios y posibilidades de intervención en Latinoamérica (pp. 265-296). Santiago de Chile: Editorial Universitaria.

Avilés, M. y Monjas, C. (2005). Estudio de incidencia de la intimidación y el maltrato entre iguales en la educación secundaria obligatoria mediante el Cuestionario sobre Intimidación y Maltrato entre Iguales. Anales de Psicología, 21(1), 27-41.

Bausela, E. (2008). Estrategias para prevenir el bullying en las aulas. Intervención Psicosocial, 17(3), 369-370.

Belsey, B. (2005). Ciberbullying: An Emerging Threat to the Always of Generation. Recuperado de https://is.gd/KWdwor

Calderero, M., Arias, B., Irurtia, M. y Caballo, V. (2011). Acoso escolar y ansiedad social en niños I: Análisis de su relación y desarrollo de nuevos instrumentos de evaluación. Revista Internacional de psicología clínica $y$ de la salud, (3), 591-609.

Ferreira, Y. y Muñoz, P. (2011). Programa de intervención en habilidades sociales para reducir los niveles de acoso entre pares o bullying. Ajayu, 9(2), 264-286.

Lazo, E., Salazar, M. y Ávalos, M. (2011). Bullying, destruyendo mi autoestima. Revista Salud, Sexualidad y Sociedad, s. p.

Ley 1620 de 2013 (15 de marzo de 2013), por la cual se crea el sistema nacional de convivencia escolar y formación para el ejercicio de los derechos humanos, la educación para la sexualidad y la prevención y mitigación de la violencia escolar. Diario Oficial n. ${ }^{\circ}$ 48733. Recuperado de https:// is.gd/LGJgza

Magendzo, A. (2011). Estrategia de intervención en bullying desde una perspectiva de derechos humanos. Recuperado de https://is.gd/7Q02oS 
Ministerio de Educación Nacional (2012). Guía de promoción de derechos humanos sexuales y reproductivos y prevención, identificación y atención: acoso escolar. Recuperado de https://is.gd/gWxV6Z

Rivers, J., Duncan, N. y Besag, V. (2007). Bullying: Manual para educadores $y$ padres. Westport: Greenwood.

\section{Bibliografía complementaria}

Colombia es uno de los países con mayores cifras de matoneo (15 de marzo de 2012). Vanguardia, recuperado de https://is.gd/fr4VAW

Monjas, I. y Avilés, J. (2004). Programa de sensibilización contra el maltrato entre iguales. Valladolid: REA.

Ortega, R. (2003). Enseñanza de prevención de la violencia en escuelas de Centroamérica (Proyecto TC/99/0011). Washington D. C.: Banco Interamericano de Desarrollo.

Ortega, R. (2005). Violencia escolar en Nicaragua: Un estudio descriptivo en escuelas de primaria. Revista mexicana de investigación educativa, x, 26.

Ortega, R. y Rey R. (2003). La violencia escolar: Estrategias de prevención. Barcelona: Graó.

Senovilla, H. (2012). Bullying: un miedo de muerte. Radiografía de la violencia entre niños y jóvenes en las aulas españolas. Recuperado de https:// is.gd/rZseiA

Teruel, J. (2007). Estrategias para prevenir el bullying en las aulas. Intervención Psicosocial, 17(3), 369-370. Recuperado de https://is.gd/tC2Ewl 



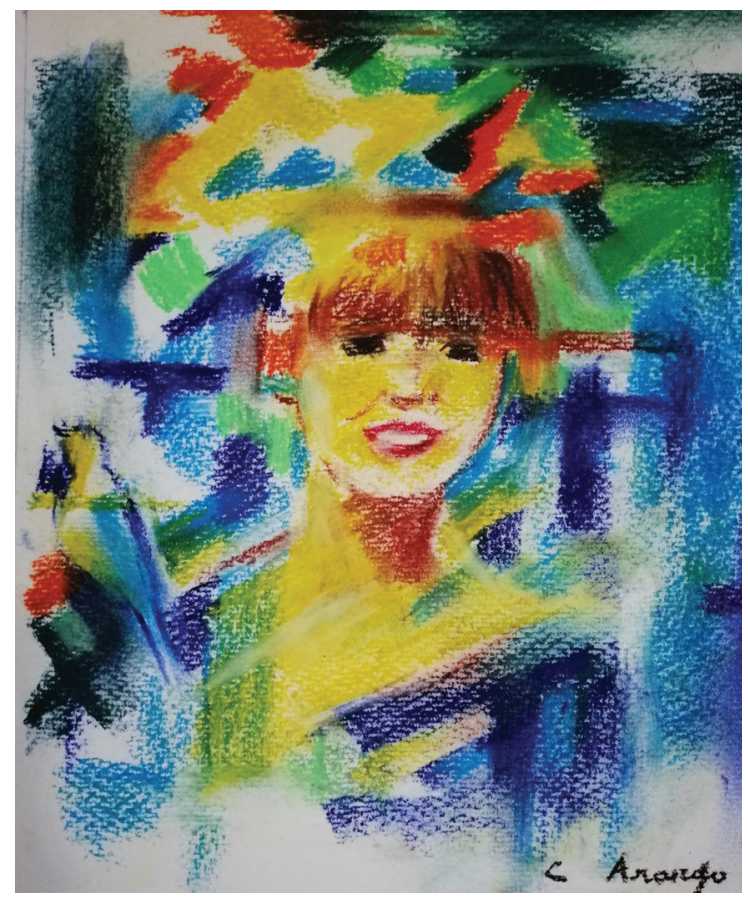

Si se habla de autoridad, para un niño hay muchas clases de autoridad: la Policía, la profesora o un adulto. Si se encuentra con un adulto cualquiera en la calle tiene que aprender a ser crítico, que sea consciente de lo que le está diciendo, que no lo esté mandando a hacer una cosa mala; pero si el niño cree que tiene que obedecer porque es un adulto, entonces hay un problema. Hay que enseñarle al niño a qué clase de autoridad le puede hacer caso, a cuál obedece y a cuál no.

Padre de familia Hogar Infantil Fundehi, barrio El Arroyo, Cazucá, Soacha, 2017 